\title{
Does Father Know Best? A Formal Model of the Paternal Influence on Childhood Social Anxiety
}

\author{
Susan M. Bögels · Enrico C. Perotti
}

Published online: 3 December 2010

(C) The Author(s) 2010. This article is published with open access at Springerlink.com

\begin{abstract}
We explore paternal social anxiety as a specific risk factor for childhood social anxiety in a rational optimization model. In the course of human evolution, fathers specialized in external protection (e.g., confronting the external world) while mothers specialized in internal protection (e.g., providing comfort and food). Thus, children may instinctively be more influenced by the information signaled by paternal versus maternal behavior with respect to potential external threats. As a result, if fathers exhibit social anxiety, children interpret it as a strong negative signal about the external social world and rationally adjust their beliefs, thus becoming stressed. Under the assumption that paternal signals on social threats are more influential, a rational cognitive inference leads children of socially anxious fathers to develop social anxiety, unlike children of socially anxious mothers. We show in the model that mothers cannot easily compensate for anxious paternal behavior, but choose to increase maternal care to maintain the child's wellbeing. We discuss research directions to test the proposed model as well as implications for the prevention and treatment of child social anxiety.
\end{abstract}

Keywords Father - Social anxiety - Etiology · Child anxiety disorders $\cdot$ Evolution

S. M. Bögels $(\square)$

Child Development and Education, University of Amsterdam, PO Box 94208, 1090 GE Amsterdam, Netherlands e-mail: S.M.Bogels@UVA.NL

E. C. Perotti

University of Amsterdam, Amsterdam, Netherlands

\section{Introduction}

Social anxiety disorder runs in families (Lieb et al. 2000; Stein et al. 1998; Tillfors et al. 2001) and breeds through (Cooper et al. 2006; Feyer et al. 1995; Reich and Yates 1988). Next to genetic factors (Hettema et al. 2005), parental modeling and rearing are thought to transmit the disorder. However, research so far has only found partial evidence for a modest role of family factors assumed to enhance or maintain child social anxiety, such as parental overprotection or control (e.g., Rapee and Spence 2004; Bögels and Stein 2009). Further, these factors are nonspecific, which means that they also show associations with other forms of psychopathology (Bögels et al. 2010a). Therefore, it can be concluded that the role of parenting and the family in the etiology of social anxiety disorders is still poorly understood.

The bulk of research on the role of parenting in child anxiety has focused primarily on mothers (e.g., Bruggen et al. 2008; McLeod et al. 2007). This may reflect a priori beliefs on the dominant role of maternal influence, but also data availability: mothers are the parent most likely to take a child to therapy and research settings. There are several problems with such a mother-dominant approach. Firstly, mother and father form a dynamic system in raising their children and might either compensate or reinforce each other's behavior. For example, behind an overprotective mother or symbiotic mother-child relationship, an absent or disengaged father may allow this relationship to operate (Levy 1943). A speculative view is that overprotective mothering may be largely a consequence of absent or "weak" fathering, rather than a distinctive causal factor in the etiology of childhood social anxiety. Second, one could argue that, as anxiety disorders are much more prevalent in women, maternal transmission should be the primary focus 
of study. However, social anxiety disorder is the only anxiety disorder that is equally common in men and in women, and the most prevalent mental disorder in men (e.g., Kessler et al. 2005; Grant et al. 2005). Third, since theories about anxiety-enhancing parenting are predominantly based on mothering, even if fathers are included in the research, their role is assessed according to a model that does not distinguish paternal from maternal functions. Fourth, it should be noted that the studies that did include fathers often suffer from missing data concerning the fathers, which is probably systematic, e.g., children living with their mother after a divorce, socially anxious fathers and fathers that are very active in the outside world are likely to be missing.

The scarcity of father research in the context of children's social development, the lack of a model that distinguishes father and mother roles, and the systematic missing data in studies that did assess fathers, may all lead to an underestimation of father effects on child social anxiety.

\section{Evidence for a Dominant Role of the Father in Child Social Anxiety}

From a broad review on the role of the father in the etiology, prevention and treatment of child anxiety in general (Bögels and Phares 2008) the following conclusions can be drawn. First, research on normal child development suggests that fathers play an important and different role than mothers in the socialization of children and in the protection of children against severe anxiety in general. Second, studies in the area of developmental psychopathology suggest that if fathers are not involved, are not warm, and do not encourage the autonomy of the child, and if they display anxiety themselves, the child is at risk for anxiety. Moreover, a meta-analysis by Bruggen et al. (2008) provides tentative support for the idea that paternal rearing is important in child anxiety. That is, the association between parental control and child anxiety was larger in studies that did include father $(n=5, d=.84)$ than in studies including mothers only $(n=18, d=.50)$, although it should be mentioned that this difference in effect size was not significant. We here review the few studies in the field of the development of specifically social anxiety in children that did include fathers.

The quality of parent-child attachment has been predominantly investigated in mothers. However, two studies investigated the attachment of both parents to their child in the context of stranger sociability, as an indication of successful coping with social anxiety. In these studies, it was shown that secure father-infant, but not mother-infant attachment, predicted stranger sociability in toddlers
(Lamb 1982; Kromelow et al. 1990). Belsky et al. (1998) conducted a longitudinal study of the observed mothering and fathering on toddler boys scoring high and low on negative emotionality on 3-year old boys' behaviour inhibition. As behaviour inhibition is generally viewed as a predisposition for social anxiety, the study is relevant in the present context. The researchers found fathers', but not mothers', rearing style to predict their young sons' inhibition level. Surprisingly, however more negative (i.e., intrusive) and less positive (i.e., sensitive) fathering forecasted less inhibition. More negative and less positive fathering may represent a more limiting and "stronger" paternal rearing style, which apparently encouraged boys to overcome their original inhibited attitude towards the external world. In another study of older children, Greco and Morris (2002) showed that fathers' non-verbal controlling behavior during an interaction with the child in which an Origami task had to be solved, was associated with social anxiety in 10- to 14-year olds. Unfortunately, mothers were not included in this study, leaving it unclear whether this was a unique father effect. Bögels et al. (2008) found that fathers with anxiety disorders (predominantly social anxiety disorder) control their anxious children, ranging in age from 8 to 18 , more during family discussion tasks than fathers without anxiety disorders. Such a difference was not found for mothers with and without anxiety disorders. With respect to treatment research, Rapee (2000) investigated whether maternal and paternal anxiety moderated the outcome of a cognitive-behavioral treatment involving parents in 95 children aged 7-16 with anxiety disorders, mostly social anxiety disorder. Interestingly, paternal but not maternal pretreatment higher levels of anxiety predicted worse outcome (more anxiety) in their children, up to 1-year follow-up. Maybe the most direct evidence for a dominant role of the father in child social anxiety comes from a recent experiment of Bögels, Stevens and Majdandžić (2010b) on children's responses towards ambiguous social situations. Children aged 9-11 had to imagine a series of stories in which they were confronted with social events including new people, while their father or mother responded in a socially anxious or social confident way (gender of the parent and type of parental response was systematically varied across stories). Children with high social anxiety were more influenced by fathers' compared to mothers' reaction, that is, they reported higher social anxiety if father responded in a socially anxious way, and lower social anxiety if father responded in a social confident way. Mother's anxious versus confident response did not significantly influence high socially anxious' children's report of social anxiety. Note however that children in general and children with low social anxiety were found to be more influenced by their mothers' compared to their fathers' reaction. This 
result suggests that mothers and fathers have different roles in the social development of their children; fathers may enhance confidence to their socially anxious offspring, whereas mothers may induce social wariness in offspring who might be socially overconfident, and therefore at risk to transgress social rules and social rejection as a result.

In sum, the very few studies that included fathers do tentatively suggest that specific paternal behavior is associated with higher or lower levels of offspring's social anxiety, more so than maternal behaviors, particularly when children are socially anxious. This father effect appears in studies of infants to adolescents. The question is why fathers, who are generally less involved in their children's rearing than mothers, would have a dominant role when it comes to their children's social anxiety.

\section{Fathers and Mothers Role in the Course of Human Evolution}

From an evolutionary perspective, ancestral men and women evolved different physical, cognitive and emotional mechanisms in order to survive and reproduce (for a review see Buss 1994). To the present day, men are on average physically taller, stronger and more aggressive than women. Paternal investment theory (Clutton-Brock 1991) accounts for many of these differences. According to this theory, both in males and females there is a conflict how much time, energy and resources to invest in mating versus parenting. As in many species including humans, paternal investment is not essential for fathers' offspring to reach the fertile age, fathers spend less time with their children than mothers across cultures and times (Geary 1998). Traditionally, women were active in caring for the children and gathering local foods. Paternal contribution to child rearing involved the use of physical strength and orientation skills at extensive search in the broader environment for providing protection and food. These differences between sexes are reflected in cognitive and behavior abilities. To illustrate, women are better at fine motor and perceptual discrimination tasks, while men are better at route-finding tasks (Geary 1998).

Although father involvement in their children has increased (Pleck 1997), to this day men invest on average less time in their offspring than women (Lamb 2000). However, human males invest greater time in providing care to their offspring than nonhuman primates (Bjorklund and Shackeford 1999; Paquette 2004). One of the explanations is that human babies are less developed and more vulnerable at birth. Their larger brain volume, needed to adapt to an increasingly complex environment, favored women who gave birth prematurely. These vulnerable human babies needed greater maternal investment in caregiving. Significant paternal investment, specifically with respect to protection from predators and provision of food (especially game), was therefore necessary to the survival of the mother-child dyad (Ellis 1992). This division of tasks enhanced children's survival rate, while reducing the lapse of time between births in humans, compared to most primates. Another unusual behavior in the human repertoire is the collaboration of father and mother in the feeding of weaned but nutritionally dependent juvenile offspring up to adulthood. For monkeys and apes, a wide spacing between births allows the female to support a single nutritionally dependent youngster while at the same time fostering and protecting a nutritionally independent juvenile. In the human family, the collaborative efforts of the male enable the female to rear not only a nursing infant but also one or more nutritionally dependent juveniles at the same time (Lancaster and Lancaster 1987).

Another aspect of human evolution that may be important for understanding paternal investment concerns the growth of human populations, due to the emergence of agriculture, to the point where natural resources (such as game or wild foods) were no longer easily gathered. For many societies this happened only 2,000-3,000 years ago. As scarcity of free resources became the norm, it made sense for parents to invest in skills that would help their children to have access to scarce resources, rather than producing maximum numbers of healthy children. This required increased skills at social competition (Lancaster and Lancaster 1987). Fathers may have a comparative advantage with respect to preparing their children for social competition. Paternal investment probably evolved from physical interaction, such as hunting or defending against external dangers to managing external social interaction (thus outside any extended family or clan structure). Indeed, unique relations have been found between paternal investment (time and income) and upward social mobility of children even when maternal characteristics were controlled (see Geary 2000).

A simplification of this distinction between paternal and maternal parenting roles is that men have specialized in confronting the external environment, managing the encounters with potentially dangerous animals and unfamiliar humans, and social competition when resources became scarce, whereas women have specialized in "internal" care tasks, such as feeding and soothing. Consistent with the assumed evolutionary advantage of men in detecting social threat, Williams and Mattingley (2006) found that, to date, men are faster in detecting angry faces in a crowd than women. If children rationally assume that skills are associated with expertise and knowledge, they would naturally rely on mothers for insight on emotional matters, e.g., who can provide comfort? At the same time, 
they would rely on fathers for insight on the external environment, namely, is the external world rich in dangers or in opportunities? Accordingly, we hypothesize that, in order to improve survival chances against external threats, children would not just develop, but possess from birth a "father knows best" attitude about the external world. This deeply rooted attitude would ensure an instinctual, and thus immediate response even in very small children, contributing to their survival. As a result, children's tendency to put more weight on paternal signals concerning the external world would become the rational norm.

In a modern society where dangerous animals have been conquered and the external environment is planned and regulated, the most complex and potentially challenging remaining threat is the behavior of other people. Thus, the external threat in such a context takes the form of social interaction. Specifically, the child forms its social confidence based on its inference whether unfamiliar people are, on average, cooperative or dangerous. As the world has much changed, the functional basis for a distinction between paternal and maternal roles may have largely or completely disappeared in developed societies. Once the rule of law ensures protection against external threats, combat skills are no longer a requirement for "external" tasks. However, humans may not have spent enough time in such a civilized environment for such a deep instinctual attitude, hard-wired in the brain from birth, to lapse. In this sense, so called "rough and tumble play", typical of fathers' interaction with their children in most cultures (e.g., Paquette et al. 2003), can be seen as a training to prepare the child for external confrontation and interaction. Empirical evidence for the assumption that children seek their mother for internal care and their father for clues about the external world was provided in two studies of Lamb (1976, 1977), demonstrating that in the first year of life, American children prefer their mother for comfort and their father for play. In line with this, Camus (2003) observed that French fathers, during a swimming lesson with their 1-, 2-, and 3-year-olds, tend to stand behind their children, so that they face their social environment, whereas mothers stand in front of their children, seeking visual contact. These results suggest that even in modern society, fathers seem to play a specific role in preparing their offspring already at a young age to deal with the external world.

\section{Evidence on Assumptions of the Father Model}

The model presented here interprets excessive social anxiety as a cognitive problem, arising from unrealistic, negative expectations about what other people will think or do in social interactions, and thus as unrealistic, negative expectations about the personal consequences of social interaction. This assumption is in line with predominant theories about social anxiety disorder (e.g., Clark and Wells 1995; Hartman 1983; Rapee and Heimberg 1997). To date, it is unclear why socially anxious people do not update these unrealistic beliefs when provided with corrective information, or how these beliefs occurred in the first place. It is likely that an innate fear of negative evaluation is universal, and is modified through the experience of positive social interaction. For example, all children go through a period of stranger anxiety at about 8 months, which might have protected them in earlier times from kidnapping (Thompson and Limber 1990). They unlearn this stranger anxiety by the experience of positive interaction with strangers and by increased social competence. Key assumptions in the present model are that (1) children look predominantly at their parents for clues on the external world, and (2) parental beliefs play an important role in the formation of (un)realistic beliefs in their offspring.

Evidence for the first assumption, that children rely predominantly on their parents' signals to interpret the external world, comes from social referencing paradigms, in which infants are exposed to their parent (mostly the mother) interacting with a stranger or an object, and afterwards infants are themselves exposed to the stranger or object. This literature shows that children as young as 11 months take the emotional displays of their parents to regulate their behavior towards new objects and people (e.g., Meltzoff 2007). Zarbatany and Lamb (1985) tested the idea that children rely more on their parent than on a stranger directly. Fourteen months old infants were exposed to a toy spider, in the presence of either their mother or a stranger who conveyed either a happy or a fearful facial expression. Infants approached the spider more when mothers conveyed happy expressions than when they conveyed fear, but showed no such differential responding to the stranger's affective display. In the context of social anxiety, the level of social anxiety expressed by mothers in interaction with a stranger as observed by their 11 months olds, predicted whether these infants behaved socially anxious towards a stranger 3 months later (Murray et al. 2008). Moreover, normal mothers who were trained to either behave socially anxious or socially confident in interaction with a stranger, showed that infants of mothers who acted socially anxious expressed more social anxiety towards the stranger afterwards (De Rosnay et al. 2006). These few studies do demonstrate that children use their parents' signals concerning the outside social world.

The second assumption, that parental beliefs are important in the formation of child beliefs in the context of anxiety, was investigated using a paradigm in which children were first confronted with ambiguous social situations 
and had to give their interpretations, then discussed the situations with their parents, and then gave their final interpretation (Barrett et al. 1996). Anxiety disordered children aged 7-14 were found to choose even more unrealistic negative interpretations concerning ambiguous social situations than would otherwise be the case after interacting with their parents. Further research using this paradigm showed that children's more negative interpretations of ambiguous events were related to parental anxious utterances during the discussion with their child (Chorpita et al. 1996) and parental negative interpretations (Bögels et al. 2003). In line, McDowell et al. (2002) found that parents' cognitive representations of social relationships were related to their children's representations. In a longitudinal study, Creswell et al. (2006) demonstrated that mothers' threat interpretation of ambiguous events predicted threat interpretations of their 11-12 year old children over time. In sum, these studies support the assumption that children's cognitive representations of threat are influenced by their parents' representations.

The next section illustrates the behavioral model. In the last section, the preventive and clinical consequences of the model are discussed, and suggestions for future research are given.

\section{A Formal Model of Inference from Parental Signals}

We present here a behavioral model which shows that child anxiety may arise from a rational cognitive process, drawing from informational clues from parental behavior. The formation of child beliefs on the external world is described as rational Bayesian inference from such clues. We analyze child and parents' behavior in a rational decision process where behavior is the response to incentives and information, and parents maximize the child's well-being.

Explaining behavior using mathematic optimization is standard in many social sciences from economics to evolutionary biology. As a closely related example, CluttonBrock (1991) describes optimal parental investment in their offspring across a wide variety of species as a Nash equilibrium in which once parental expenditure reaches some threshold level, each parent should respond to increases in care by its partner by reducing their own expenditure. The advantage of formalizing an idea that can be well understood in plain language is that it provides an explicit mechanism on the determinants of behavior whose assumptions are open to scrutiny and testing. It also allows to quantify the effect of individual features, such as the degree of paternal anxiety, and to derive the direct behavioral consequences for other individuals, such as the mother. Finally, an explicit mechanism allows to measure the response to change in specific parameters, such as paternal influence. The validity of these formal results, of course, can only be validated by empirical evidence supporting the model assumptions and their congruence with predicted outcomes.

The model studies the consequences of the child's instinctive beliefs about the relative efficiency of the two parents at providing clues about the external world. The child observes maternal and paternal actions and forms own beliefs on social risks. We define an individual as socially anxious if (s)he has an excessively negative assessment of "external dangers", namely the likelihood of negative social interaction. A child will become social anxious if the parental clues suggest social interaction will result in a negative experience. A positive social experience (e.g., a cooperative response) results in a gain, defined as $\mathrm{G}>0$, while a loss from an aggressive response is defined as $\mathrm{L}<0$. Let the perceived probability of a good experience be $\mathrm{p}$. For any individuals with belief $\mathrm{p}$, the expected result of social interaction is $\mathrm{pG}+(1-\mathrm{p}) \mathrm{L}$. Thus, the expected social interaction $\mathrm{E}(\mathrm{s})$, may be positive or negative, depending on the subjective belief $\mathrm{p}$. We define the perceived probability of cooperative behavior $p$ and the expected value $\mathrm{E}(\mathrm{s})$ as measures of social confidence.

As a benchmark, assume that the objective probability of beneficial social interaction is sufficiently large that expected gains from social interaction exceed expected losses (so that normal people will not be anxious; see Table 1a):

$\mathrm{E}(\mathrm{s} \mid \mathrm{p})=\mathrm{pG}+(1-\mathrm{p}) \mathrm{L}>0$

According to this simple expression, an individual is socially anxious if she or he expects a loss from social interaction. Such individuals will rationally seek to minimize social interaction. Their behavior may be observed by their children, who use this information in forming their own beliefs. Specifically, children infer social confidence of their mother and father, denoted respectively $\mathrm{p}_{\mathrm{M}}$ and $\mathrm{p}_{\mathrm{F}}$, from their individual behavior. So the child's final view on social interaction reflects informational clues from parental behavior.

A child who has formed an own opinion $\mathrm{E}(\mathrm{s})$ also receives parental care, a choice which optimizes child well being at an acceptable cost to the parent. A simple description of the child's well being is a concave utility

$\mathrm{U}[\mathrm{c}+\mathrm{E}(\mathrm{s})]$

where $c$ represents soothing care, and $\mathrm{E}(\mathrm{s})$ is the expected gain from social interaction.

We first study the cognitive consequences of the paternal action on the child; later we consider its behavioral 
Table 1 Prove for a formal model of inference of parental signals

Panel A

A normal person expects a gain from social interaction. Formally, this means their assessment of s, the gain from social interaction, is positive, as the chance $\mathrm{p}$ of a positive interaction $\mathrm{G}$ exceeds their chance of a negative interaction $\mathrm{L}$ :

$\mathrm{E}(\mathrm{s} \mid \mathrm{p})=\mathrm{pG}+(1-\mathrm{p}) \mathrm{L}>0$

Individuals are socially anxious if they have subjective beliefs $\mathrm{p}<\mathrm{p}^{*}=-\mathrm{L} /(\mathrm{G}-\mathrm{L}$ ), so that they expect a loss from social interaction (in the simple case when $\mathrm{G}=-\mathrm{L}$, an individual is socially anxious if his or her subjective assessment of $\mathrm{p}$ is below $1 / 2$ ). Such individuals will rationally seek to minimize social interaction

Panel B

The child interprets the father's action $\mathrm{a}_{\mathrm{F}}$ and mother's action $\mathrm{a}_{\mathrm{M}}$ in an assessment of paternal and maternal social confidence. The child's own belief is a weighted average of the two signals, each weighted by its perceived precision. Let the perceived precision (statistically, the reciprocal of the perceived variance of the estimate error) of the paternal signal be $\theta_{\mathrm{F}}$, while it is $\theta_{\mathrm{M}}$ for the mother. The child's resulting belief on $\mathrm{p}$ will be:

$$
\begin{aligned}
\mathrm{E}(\mathrm{p}) & =\frac{\mathrm{E}\left(\mathrm{p} \mid \mathrm{a}_{\mathrm{F}}\right) \theta_{\mathrm{F}}+\mathrm{E}\left(\mathrm{p} \mid \mathrm{a}_{\mathrm{M}}\right) \theta_{\mathrm{M}}}{\theta_{\mathrm{F}}+\theta_{\mathrm{M}}} \\
& =\mathrm{p}_{\mathrm{F}} \theta_{\mathrm{F}}+\mathrm{p}_{\mathrm{M}}\left(1-\theta_{\mathrm{F}}\right)
\end{aligned}
$$

Our assumption is that the child attributes to the father greater expertise regarding the external social environment relative to the mother.

Proposition 1 is immediately proven under this simple condition:

Condition $1 \quad \theta_{\mathrm{F}} \mathrm{p}_{\mathrm{A}}+\theta_{\mathrm{M}} \mathrm{p}_{\mathrm{M}}<\mathrm{p} *$

which is true if the father is very anxious (i.e., $\mathrm{p}_{\mathrm{F}}$ is low) or if paternal behavior is very influential (i.e., $\theta_{\mathrm{F}}$ is high).

Proof: Suppose the father is anxious, but the mother is not (if both are anxious, the proof is trivial). Because $\theta_{\mathrm{F}}>\theta_{\mathrm{M}}$ (the child assumes that the father's information about the external world is more precise than the mother's), the child inference E(p) will be dominated by the weight of paternal anxiety. Under Condition I, their posterior belief is below the threshold for social anxiety $\mathrm{p}^{*}$

Panel C

The mother faces increasing costs of providing more comfort, as described by a function $\mathrm{f}(c)$, increasing and convex in $c$. This implies that more care is increasingly costly as it reduces income, sleep, or personal freedom. The optimal choice of maternal care $c$ will maximize her preference, which equals child comfort minus her cost of providing maternal care:

$\mathrm{Max}_{\mathrm{c}} \mathrm{E} \mathrm{U}[\mathrm{c}+\mathrm{E}(\mathrm{s})]-f(c)$

The optimal level of care $c^{*}$ satisfies the first order condition for maximization:

$\partial \mathrm{EU}\left(\mathrm{c}^{*}, \mathrm{E}(\mathrm{s})\right) / \partial \mathrm{c}=\partial \mathrm{f}\left(\mathrm{c}^{*}\right) / \partial \mathrm{c}$

which states that the mother will rationally provide care till the point where there is no net gain, namely, when the marginal increase in child comfort equals her marginal cost in providing it. Note that social confidence $\mathrm{E}(\mathrm{s})$ is not directly affected by care, and vice versa.

Proposition 2 states that maternal care increases when a child has an anxious father and thus a lower $\mathrm{E}(\mathrm{s})$. The proof follows directly from the optimal mother's choice of care $c^{*}$, which says that she will supply care until its marginal cost equals the child's marginal utility. Since lower social confidence $\mathrm{E}(\mathrm{s})$ reduces the child's overall well being, it increases the comfort value of maternal care. The mother responds by increasing the amount of care she supplies, till the child's marginal utility equals her increased cost of care

consequences. We focus on the two cases when either only the father or the mother are anxious.

\section{Optimal Behavioral Choices}

The child's own belief is a weighted average of the two signals, each weighted by its perceived precision. Let the perceived precision of paternal information be $\theta_{\mathrm{F}}$, while it is $\theta_{\mathrm{M}}$ (equal to $1-\theta_{\mathrm{F}}$ ) for the mother. Using classic statistical inference, the child's resulting belief on $\mathrm{p}$ will be $\mathrm{p}_{\mathrm{F}}$ $\theta_{\mathrm{F}}+\mathrm{p}_{\mathrm{M}}\left(1-\theta_{\mathrm{F}}\right)$ (see Table $\left.1 \mathrm{~b}\right)$.

Our fundamental assumption is that the child attributes to the father greater expertise regarding the external social environment relative to the mother, so that its signal is weighted more: $\theta_{\mathrm{F}}>\theta_{\mathrm{M}}$. In other words, the child assumes that the father's information about the external world is more precise than the mother's. We take this as a prior (hard wired) belief, and not the result of observation.
We can now state our basic result (proven in Table 1c):

Proposition 1 When the father is very anxious (i.e., $p_{F}$ is low) or if paternal behavior is very influential (i.e., $\theta_{F}$ is high), children of an anxious father will be anxious.

The intuition is simple. When paternal influence is large and the father is sufficiently anxiety, its influence overcomes the maternal signal. So an anxious father will induce a posterior belief in the child that social interaction is damaging and should be avoided. For the same reason, it is easy to show that anxious mothers are much less likely to create child anxiety. When the mother is anxious (with a low p) but the father has a normal assessment $\mathrm{p}$, the child is less likely to develop social anxiety since maternal signals in this domain carries less influence. Intuitively, greater paternal influence $\left(\theta_{\mathrm{F}}>\theta_{\mathrm{M}}\right)$ can more easily compensate for anxious maternal behavior than vice versa. On the other hand, a mother will have a harder time trying to compensate for an anxious partner. 
The next section studies what parents may do when the child is anxious. Since social anxiousness reduces the child's well being, parents can try to compensate by increasing care beyond what they may choose to do for a normal child. We assume that the compensating care is provided by the mother, who may have a comparative advantage over her partner in this domain (in contrast to the perceived ability in the external world).

\section{Choice of Maternal Care}

The model allows to show that the mother responds to an anxious child by increasing internal comfort, at some personal costs. Increasing care is costly as it reduces income, sleep, or personal freedom.We assume that care does not change social confidence $\mathrm{E}(\mathrm{s})$.

The optimal choice of maternal care $c$ will maximize the objective function of the mother, which equals child comfort minus her cost of providing maternal care:

$\operatorname{Max}_{\mathrm{c}} \mathrm{E}[\mathrm{c}+\mathrm{E}(\mathrm{s})]-\mathrm{f}(\mathrm{c})$

where $\mathrm{f}(\mathrm{c})$ measures the cost of maternal care (see Panel C).

The mother will rationally provide care till the point where there is no net gain, namely, when the marginal increase in child comfort equals her marginal cost in providing it. The solution to this simple optimization provides our second main result:

Proposition 2 Anxious children will receive more maternal care, as the mother seeks to boost the child's well being to compensate for the discomfort caused by social anxiety. The amount of compensating care increases with the level of child anxiety.

The intuition is that the mother chooses a higher amount of care (at a higher personal cost) to compensate for the reduced level of well being coming from social interaction.

Figure 1 presents this maternal choice of care as a function of paternal anxiety. Clearly, the mother exerts more care as the father is more anxious. The different graph lines indicate maternal care choices for different levels of paternal influence $\theta$. As the anxious father becomes more influential, the child becomes less confident at a faster rate as paternal anxiety increases. In this case, maternal care must increase at a faster rate to compensate for the loss of well being of the child.

More maternal care probably contributes to make the home experience more pleasant than perceived social experiences. So the child of an anxious father may become even less socially oriented due to the compensating caring effort of the mother, an unintended consequence. The compensating care by the mother may be generally perceived as "overprotection". In our interpretation, in this case it has nothing to do with protecting the child from the external world.

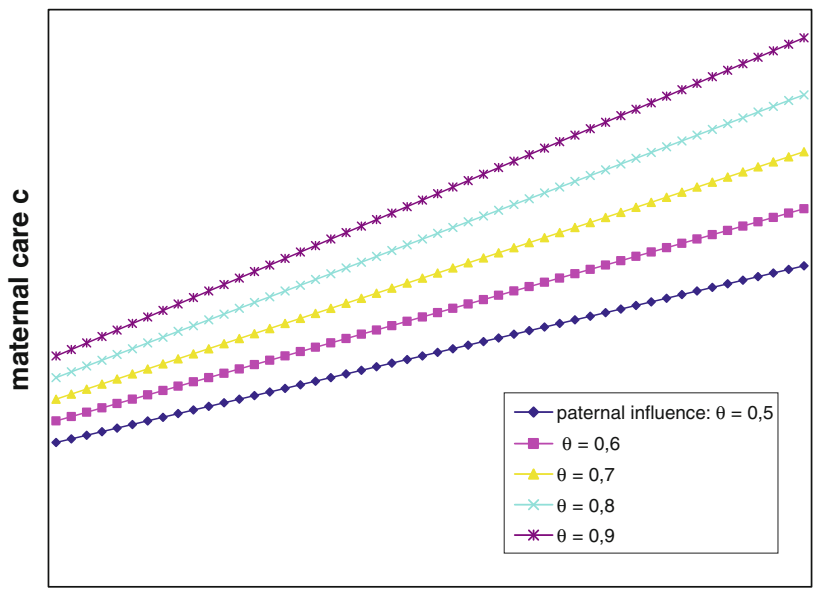

paternal anxiety $(p-p F)$

Fig. 1 Maternal choice of care as a function of paternal anxiety

Dynamic Extension: Child's Choice of Social Interaction

We here discuss the behavioral consequences on child social behavior of our cognitive model. Any child has the option to engage actively in, or avoid social interaction, and will make a rational choice based on its beliefs on the benefit of social experience. Children who choose more social interaction will develop independent information on its benefits, and will use it to update their initial beliefs. These experiences should decrease social anxiety. On the other hand, anxious children who avoid social interaction will have a reduced learning experience. Thus, if a child draws from paternal behavior a negative assessment on the potential threat associated with social interaction, it will fail to test this belief, and the belief will persist even when incorrect. This analysis leads to the prediction that social anxiety may run in families with anxious fathers for generations, even when no genetic transmission exists.

The model also suggests that mothers will seek to maintain the well being of an anxious child by increasing maternal care. To the extent that this choice increases the utility to staying at home, it will also contribute to reduced social interaction and less learning about its benefits, reinforcing any negative child beliefs.

\section{Discussion}

Our decision theoretic model has shown that the child's instinctive inference process may be responsible for the intergenerational transmission of social anxiety disorder through anxious father behavior. The model therefore clearly predicts that fathers with social anxiety disorder, more than mothers with social anxiety disorder, will 
transmit their anxiety on their offspring. The most interesting results concern the interaction between paternal anxiety and maternal behavior, and their cumulative effect on the social anxiety and wellbeing of the child. Increasing paternal anxiety induces an increase in maternal care, as the mother compensates for the lower wellbeing of a more anxious child. This choice may actually increase child's anxiety through lack of exposure.

The model results need to be validated by empirical evidence on the validity of its assumptions and implied correlations. While mostly indirect evidence exists on children's tendency to put more weight on the social signal of fathers relative to mothers, testing this specific conjecture requires experimental designs. Paradigms relying on conditioning, informational learning, and modeling, in which the effects of fathers' versus mothers' responses on child social anxiety are evaluated, can examine the conjecture that fathers' anxious versus social confident model should have more impact on child social anxiety than mothers'. Once the primary prediction of the dominance of fathers' social signal has been tested, the model suggests various research strategies. The prediction that mothers compensate for the social anxiety of the father by increasing care could be investigated in experimental tasks such as the social referencing task (Feinman and Lewis 1983), studying the behavior of the mother towards the child while the father is interacting with a stranger, and vice versa. Next to experimental paradigms, longitudinal studies are needed in which the social anxiety of both mother and father, in interaction with the developing infant, is examined. The first author is currently undertaking such a study.

The model presented here is restricted to social anxiety. There are several reasons for focusing on social anxiety, most importantly because of the role of social competition in the evolution of the human sort, and more pragmatically because social anxiety disorder runs in men in the same rate as in women. However, the father may have an equally or even more important influence on other types of child anxiety that concern the external world, such as fear of getting lost, fear of animals, and fear of getting hurt. Therefore, the model could be extended to non-social domains of anxiety.

A note should be made about children who are raised by two parents of the same gender. These children cannot overvalue fathers' signal over mothers' when it comes to possible social threat, simply because there are two or no fathers. On the other hand, even in households with couples of the same gender a task division may be apparent, in which one parent is more playful and challenging, whereas the other is more caring. Patterson (1995) found that, in two-mother couples, biological mothers reported greater involvement in childcare, whereas non-biological mothers spend longer hours in paid work. This raises the possibility that, even in same-gender families, the usual role division concerning childcare, which characterizes heterosexual partnership, may be evident (Parke 2004). Whether a similar biological/non-biological role differentiation also occurs in two-father couples, and whether the non-biological parent in same-gender couples enacts other aspects of traditional father roles, such as a physical play style, remains to be investigated. It is furthermore likely that the more socially anxious person of a same-gender parent couple will specialize more in the maternal role of caring, whereas the less socially anxious person will specialize in the paternal role of play and challenging.

The father role as presented here was restricted to cognitive signal learning and did not take into account more complex human interactions such as play. Certain forms of play, such as "rough and tumble" and other (physically) more challenging play, that are predominantly the domain of the father, were found to be associated with a socially confident development in children (see Parke 2004; Paquette 2004). During such exciting play, children may learn to interpret the internal arousal that is elicited (e.g., accelerated heart activity) as "fun" rather than "fear". As a result, they may become better equipped to tolerate such arousal in other social interactions. As lack of tolerance for heightened arousal plays an important role in the etiology of social anxiety (e.g., Bögels 2006), this may be another pathway through which fathers may protect their children against a socially anxious development. Moreover, during exciting play children experiment with taking different roles (e.g., being aggressive, playful), and with different responses towards behavior of the play partner (e.g., aggression, teasing). Also, fathers model how to keep others positively engaged. Therefore, paternal wild play in many different ways contributes to the development of children's social confidence. Research is necessary to further understand the functions of paternal play in the context of (prevention of) child social anxiety.

One of the assumptions of the model presented was that children take their parents as the predominant models. From a cognitive schema theory perspective, once an infant has formed a threat scheme, based on its early experiences with his primary male caregiver, usually the father, it will have a preference for processing schema-congruent information (Clark and Wells 1995). On the other hand, the child may of course be able to put their father's behavior in some perspective. In particular, a possible corrective mechanism may arise from the very cause of the problem, namely the stronger influence of father's social behaviour. Could it be that children look at other fathers, male teachers, older brothers, etc. to seek additional evidence concerning the signal their father has given that their social environment is dangerous? If so, this would represent a possible therapeutic 
approach. Research is needed to examine the effects of stepfathers, male caregivers in kindergarten, male teachers, on the development of social anxiety in at risk children because of a socially anxious father.

A limitation of the model presented here on the comparative advantage of fathers in the etiology of child social anxiety is that it does not take child characteristics into account, such as the temperament or inherited social anxiety of the child, child gender, and child age or development. Children with a behaviorally inhibited temperament, for example, may be more susceptible for parental influence in general or for paternal influence, as the study of Bögels et al. (2010b) suggests. Child gender is another important child characteristic in considering paternal comparative advantage, particularly from an evolutionary perspective. That is, boys may need to be more socially risk taking than girls in order to have the best reproductive outcome, and it could be speculated that they will therefore be more susceptible for fathers' signals. Note however that Bögels et al. (2010b) found no differences in fathers' versus mothers' influence on boys' and girls' social anxiety aged 8-11. The (developmental) age of the child may also interact with paternal versus maternal influence. For example, some studies suggest that fathers' role is particularly important during adolescence (see Bögels and Phares 2008, for a review).

From a broader perspective, it should be noted that the etiology of social anxiety is likely to be determined by the (interaction of) multiple factors, such as child characteristics, parent-child interaction, attachment, marital functioning, family functioning, peers, school, and sociocultural factors. The model presented here is therefore not an attempt to explain the etiology of child social anxiety, but an attempt to model one specific facet of social learning, namely social referencing or signal learning, taking into account both parents and their possible evolutionary-based different influence. The advantage of such a simplistic rather than heuristic model is that it leads to testable hypotheses and can be refuted if experimental research does not confirm it.

If future research shows that fathers' signal is indeed more influential than mothers', social role modeling is an alternative theory that could explain this result next to the here proposed evolutionary-based model. That is, also in modern society, men are socialised more to risk taking and competition in the external social world (e.g., initiate a date, apply for a job, ask for a salary raise) than women, and in fact, take more risks in most domains (e.g., Byrnes et al. 1999). As a result, fathers who behave more socially anxious, would be more "salient" or "out-of-character" to children, and therefore may have more influence. In order to test these alternative theories, evolution versus socialcultural roles, against each other, designs should be developed in which evolutionary- relevant and evolutionary non-relevant ambiguous stimuli could be tested on a possible dominant paternal influence (e.g., fathers' and mothers' response to a robot dinosaur versus a car).

Finally, gender role theories offer another interesting perspective on different father and mother roles on children's social development. According to Gilligan (1987), for boys and men, separation and individuation are tied to gender identity since separation from the mother is essential for the development of masculinity. For girls and women, issues of feminine identity do not depend on separation from the mother or on the progress of individuation. Gilligan reasons that therefore, women recognise the continuing importance of attachment in the human life cycle, while men (and society) stresses separation, autonomy, and individuation. The implications of this theory for gender differences in parenting are that mothers can be expected to focus more on attachment and fathers more on autonomy encouragement. It could further be hypothesized that social anxiety disorder in fathers may hinder stimulating autonomy and individuation in their offspring.

Irrespective of whether evolutionary theory, social role modeling, gender role perspective, or a combination, explains the findings, if future research will show that fathers indeed have a comparative advantage in signaling social threat and as a social role model, the implications for treatment and prevention of social anxiety are numerous. The general tendency to predominantly work with mothers in the treatment and prevention of child anxiety disorders (see Bögels and Phares 2008) appears far from optimal from the present model. The clinical practice is often to help mothers to become less overprotective towards their anxious child, and rather encourage their anxious child towards exposure. But if mothers' overprotection might be in part a response to fathers' anxious behavior, and fathers might be more convincing in encouraging and modeling their child to be courageous in doing exposure, it might be more effective to involve fathers than mothers in therapy. If the father has indeed a comparative advantage in protecting the child against social anxiety and avoidance, effective prevention of child social anxiety should primarily focus on the father. One way to prevent child social anxiety would be to treat paternal social anxiety. Furthermore, prevention of child social anxiety should include promoting paternal behaviors such as playfulness and social risk-taking, according to the present model. In child anxiety prevention programs in which parents are involved, for example by running parent groups, parents that follow the course are mostly mothers. Initiating specific father interventions (for example, father groups) may not only promote the development of knowledge on father-specific roles to protect children against extreme social anxiety, but will also encourage fathers to attend parenting courses. 
Do children think that fathers know best? The answer to this question could be an important piece of information currently lacking in our knowledge of the etiology of social anxiety disorder, and may have far reaching implications for prevention and treatment of this prevalent and severe mental disorder.

Acknowledgement This study was supported by an Innovation Research Vidi NWO grant, number 452-05-345 to the first author.

Open Access This article is distributed under the terms of the Creative Commons Attribution Noncommercial License which permits any noncommercial use, distribution, and reproduction in any medium, provided the original author(s) and source are credited.

\section{References}

Barrett, P. M., Rapee, R. M., Dadds, M. R., \& Ryan, S. M. (1996). Family enhancement of cognitive style in anxious and aggressive children. Journal of Abnormal Child Psychology, 24, 187-203.

Belsky, J., Hsieh, K., \& Crinic, K. (1998). Mothering, fathering and infant negativity as antecedents of boys' externalizing problems and inhibition at age 3: Differential susceptibility to rearing experiences? Development and Psychopathology, 10, 301-319.

Bjorklund, D. F., \& Shackelford, T. K. (1999). Differences in parental investment contribute to important differences between men and women. Current Directions in Psychological Science, 8, 86-89.

Bögels, S. M. (2006). Task concentration training versus applied relaxation followed by cognitive therapy for social phobic patients with fear of blushing, trembling and sweating. Behaviour Research and Therapy, 44, 1199-1210.

Bögels, S. M., Alden, L., Beidel, D., Clark, L., Pine, D., Stein, M., et al. (2010a). Social anxiety disorder: Questions and answers for the DSM-V. Depression and Anxiety, 27, 168-189.

Bögels, S. M., Bamelis, L., \& Van der Bruggen, C. (2008). Parental rearing as a function of parent's own, partner's, and child anxiety status: Fathers make the difference. Cognition and Emotion, 22, 522-538.

Bögels, S. M., \& Phares, V. (2008). The role of the father in the development, prevention and treatment of childhood anxiety disorders: A review and new model. Clinical Psychology Review, 28, 539-558.

Bögels, S. M., \& Stein, M. (2009). Social anxiety disorder; towards the DSM-V. American Psychiatric Associations Monographs.

Bögels, S. M., Stevens, J., \& Majdandžić, M. (2010b). Parenting and social anxiety: Fathers' versus mothers' influence on their children's anxiety in ambiguous social situations. Clinical Child Psychology and Psychiatry.

Bögels, S. M., Van Dongen, L., \& Muris, P. (2003). Family influences on dysfunctional thinking in anxious children. Infant and Child Development, 12, 243-252.

Bruggen, C. O., van der Stams, G. J. M., \& Bögels, S. M. (2008). Parental control and parent and child anxiety: A meta-analytic review. Clinical Child Psychology and Psychiatry, 49, $1257-1269$.

Buss, D. M. (1994). The evolution of desire. New York: Basic Books.

Byrnes, J. P., Miller, D. C., \& Schafer, W. D. (1999). Gender differences in risk taking: A meta-analysis. Psychological Bulletin, 125, 367-383.

Camus, J. L. (2003). Väter: Die Bedeuting des Vaters für die psychische Entwicklung des Kindes. Weinheim, Basel: Beltz Verlag.
Chorpita, B. F., Albano, A. M., \& Barlow, D. H. (1996). Cognitive processes in children: Relation to anxiety and family influences. Journal of Clinical Child Psychology, 25, 170-176.

Clark, D. M., \& Wells, A. (1995). A cognitive model of social phobia. In R. G. Heimberg, M. R. Liebowitz, D. A. Hope, \& F. R. Schneier (Eds.), Social phobia: Diagnosis, assessment, and treatment (pp. 69-93). New York, London: Guilford.

Clutton-Brock, T. H. (1991). The evolution of parental care. In J. R. Krebs \& T. Clutton-Brock (Eds.), Monographs in behavior and ecology. Princeton: Princeton University Press.

Cooper, P. J., Fearn, V., Willets, L., Seabrook, H., \& Parkinson, M. (2006). Affective disorders in the parents of a clinical sample of children with anxiety disorders. Affective Disorders, 93, 205-212.

Creswell, C., O'Connor, T. G., \& Brewin, C. R. (2006). A longitudinal investigation of mother and child anxious cognitions. Cognitive Therapy and Research, 30, 135-147.

Ellis, B. J. (1992). The evolution of sexual attraction: Evaluative mechanisms in women. In J. H. Barkow, L. Cosmides, \& J. Tooby (Eds.), The adapted mind: Evolutionary psychology and the generation of culture. Oxford University Press.

Feinman, S., \& Lewis, M. (1983). Social referencing at ten months: A second order effect on infants' responses to strangers. Child Development, 54, 878-887.

Feyer, A., Mannuzza, S., \& Chapman, T. (1995). Specificity in familial aggregation of phobic disorders. Archives of General Psychiatry, 52, 564-573.

Geary, D. C. (1998). Male, female: The evolution of human sex differences. Washington, DC: American psychological Association.

Geary, D. C. (2000). Evolution and proximate expression of human paternal investment. Psychological Bulletin, 126, 55-77.

Gilligan, C. (1987). Women's place in men's life cycle. In S. Harding (Ed.), Feminism and methodology. Social science issues. Bloomington: Indiana University Press.

Grant, B. F., Hasin, D. S., Blanco, C., et al. (2005). The epidemiology of social anxiety disorder in the United States: Results from the national epidemiologic survey on alcohol and related conditions. Journal of Clinical Psychiatry, 66, 1351-1361.

Greco, L. A., \& Morris, T. L. (2002). Paternal child-rearing style and child social anxiety: Investigation of child perceptions and actual father behavior. Journal of Psychopathology and Behavioral Assessment, 24, 259-267.

Hartman, L. M. (1983). A meta-cognitive model of social anxiety: Implications for treatment. Clinical Psychology Review, 3, 435-456.

Hettema, J. M., Prescott, C. A., Myers, J. M., Neale, M. C., \& Kendler, K. S. (2005). The structure of genetic and environmental risk factors for anxiety disorders in men and women. Archives of General Psychiatry, 62, 182-189.

Kessler, R. C., Chiu, W. T., Demler, O., Merikangas, K. R., \& Walters, E. E. (2005). Prevalence, severity, and comorbidity of 12-month DSM-IV disorders in the national comorbidity survey replication. Archives of General Psychiatry, 62, 617-627.

Kromelow, S., Harding, C., \& Touris, M. (1990). The role of the father in the development of stranger sociability during the second year. American Journal of Orthopsychiatry, 60, 521-530.

Lamb, M. E. (1976). Interactions between two-year-olds and their mothers and fathers. Psychological Reports, 38, 447-450.

Lamb, M. E. (1977). Father-infant and mother-infant interaction in the first year of life. Child Development, 48, 167-181.

Lamb, M. E. (1982). Paternal influences on early socio-emotional development. Journal of Child Psychology and Psychiatry and Allied Disciplines, 23, 185-190.

Lamb, M. E. (2000). The history of research on father involvement: An overview. Marriage and Family Review, 29, 23-42. 
Lancaster, J. B., \& Lancaster, C. S. (1987). The watershed: Change in parental investment and family formation strategies in the course of human evolution. In J. B. Lancaster, J. Altmann, et al. (Eds.), Parenting across the lifespan: Biosocial dimensions (pp. 187-205). Hawthorne: Aldine.

Levy, D. (1943). Maternal overprotection. New York: Columbia University Press.

Lieb, R., Wittchen, H., Hoflet, M., Fuetsch, M., Stein, M. B., \& Merikangas, K. R. (2000). Parental psychopathology, parenting styles, and the risk of social phobia in offspring. Archives of General Psychiatry, 57, 859-865.

McDowell, D. J., Parke, R. D., \& Spitzer, S. (2002). Parent and child cognitive representations of social situations and children's social competence. Social Development, 11, 469-486.

McLeod, B. D., Wood, J. J., \& Weisz, J. R. (2007). Examining the association between parenting and child anxiety: A metaanalysis. Clinical Psychology Review, 27, 155-172.

Meltzoff, A. N. (2007). 'Like me': A foundation for social cognition. Developmental Science, 10, 126-134.

Murray, L., de Rosnay, M., Pearson, J., Bergeron, C., Schofield, E., Royal-Lawson, M., et al. (2008). Intergenerational transmission of social anxiety: The role of social referencing processes in infancy. Child Development, 79, 1049-1064.

Paquette, D. (2004). Theorizing the father-child relationship: Mechanisms and developmental outcomes. Human Development, 47, 193-219.

Paquette, D., Carbonneau, R., Dubeau, D., Bigras, M., \& Tremblay, R. E. (2003). Prevalence of father-child rough-and-tumble play and physical aggression in preschool children. European Journal of Psychology of Education, 18, 171-189.

Parke, R. D. (2004). Developmental family. Annual Review of Psychology, 55, 365-399.

Patterson, C. J. (1995). Families of the baby boom: Parents' division of labor and children's adjustment. Developmental Psychology, $31,115-123$.
Pleck, J. H. (1997). Paternal involvement: Levels, sources, and consequences. In M. E. Lamb (Ed.), The role of the father in child development (3rd ed ed., pp. 66-103). New York: Whiley.

Rapee, R. M. (2000). Group treatment of children with anxiety disorders: Outcome and predictors of treatment response. Australian Journal of Psychology, 52, 125-129.

Rapee, R. M., \& Heimberg, R. G. (1997). A cognitive-behavioral model of anxiety in social phobia. Behaviour Research and Therapy, 35, 741-756.

Rapee, R. M., \& Spence, S. H. (2004). The etiology of social phobia: Empirical evidence and an initial model. Clinical Psychology Review, 24, 737-767.

Reich, J., \& Yates, W. (1988). Family history of psychiatric disorders in social phobia. Comprehensive Psychiatry, 29, 72-75.

Rosnay, M., de Cooper, P. J., Tsigaras, N., \& Murray, L. (2006). Transmission of social anxiety from mother to infant: An experimental study using a social referencing paradigm. Behaviour Research and Therapy, 44, 1165-1175.

Stein, M. B., Chartier, M. J., Hazen, A. Z., Kozak, M. V., Tancer, M. E., Lander, S., et al. (1998). A direct-interview family study of generalized social phobia. American Journal of Psychiatry, 155, 90-97.

Thompson, R. A., \& Limber, S. P. (1990). 'Social anxiety'in infancy: Stanger and separation reactions. In H. Leitenberg (Ed.), Handbook of social and evaluation anxieties (pp. 85-137). New York: Plenum.

Tillfors, M., Furmark, T., Ekselius, L., \& Fredrikson, M. (2001). Social phobia and avoidant personality disorder as related to parental history of social anxiety: A general population study. Behaviour Research and Therapy, 39, 289-298.

Williams, M., \& Mattingley, J. (2006). Do angry men get noticed? Current Biology, 16, 402-404.

Zarbatany, L., \& Lamb, M. (1985). Social referencing as a function of information source: Mothers versus strangers. Infant Behaviour and Development, 8, 25-33. 